\title{
Type- D Personality and Burden among the Caregivers of Neurological Patients
}

\author{
Remita Chattopadhyay $^{1}$, Dr Anuradha Sharma ${ }^{2}$
}

\section{ABSTRACT}

Care giving itself is a self rewarding task; however it is often associated with physical, emotional, social, financial burden (Chadda, 2014) especially in cases of chronic or terminal illness. But not much of the studies have focused on the internal triggers like negative affectivity and social inhibition characterized by Type D Personality to assess burden among the caregivers. This cross sectional study examines the correlation between Type-D personality and the burden experienced by the caregivers of neurological patients.110 primary caregivers were assessed using DS14 and Zarit Burden Interview (ZBI) whose family members were suffering from neurological illness at least for past 3 months. Data analysis showed a high amount of burden experienced by primary caregivers of neurological illness of Type D personality in males as well females $(\mathrm{p}<0.01)$ and further statistical analysis revealed a significant positive correlation between burden experienced and presence of Social Inhibition and Negative affectivity among males as well female primary caregivers of neurological patients $(\mathrm{p}<0.05)$. But no significant difference was found between male and female caregiver burden and male female caregivers with Type $\mathrm{D}$ personality $(\mathrm{p}<0.05)$. Therefore it is important to develop screening, assessment and intervention strategies for Type D personality individuals especially for primary caregivers, healthcare professionals, employees in organizations to protect them against burnout or developing any chronic illness.

Keywords: Primary caregivers, Type D personality, Burden, Burnout, Negative Affectivity, Social Inhibition

Family is the pillar of support to any kind of any disability, disorder or illness. Without their care and support we are often handicapped within the society. So, the act of care giving is rewarding in itself. But on the unfortunate side care giving can be equally strenuous after a period of time, be it for parents or for spouses or for the children for their near ones even. The act

\footnotetext{
${ }^{1}$ Research Scholar, Clinical Psychology, Amity University, Noida, Uttar Pradesh, India

${ }^{2}$ Assistant Professor, Amity University, Noida, Uttar Pradesh, India

*Responding Author

Received: March 15, 2017; Revision Received: March 29, 2017; Accepted: March 30, 2017

(C) 2017 Chattopadhyay R, Sharma A; licensee IJIP. This is an Open Access Research distributed under the terms of the Creative Commons Attribution License (www.creativecommons.org/licenses/by/2.0), which permits unrestricted use, distribution, and reproduction in any Medium, provided the original work is properly cited.
} 
of care giving is often associated with increased physical, emotional, social, financial burden (Chadda, 2014) specially in cases of disorders with poor prognosis of recovery or in case of terminal illness. Thus such a stage of burden among the caregivers has also been known as "caregiver syndrome" or caregiver fatigue" by the medical fraternity. This stage of burden often leads to caregiver burnout when the caregivers are unable to cope with this inexhaustible stress and get emotionally exhausted and their positive affectivity may often lead to negative affect and unconcerned behavior.

Type D personality or Distressed Personality is characterized by tendency towards negative affectivity (e.g. worry, irritability, gloom) and social inhibition (e.g. reticence and a lack of selfassurance) (Denollet.J, 2000). Negative affectivity is often characterized by dysphoria, tension, negative self image of oneself, attention bias to stressful events with negative appraisals and higher interpersonal stressors. Whereas social inhibition is often characterized by tendency to inhibit emotional expression, avoid interpersonal conflict through excessive control over self expression, social inhibition and withdrawal and high amount of reticence and lack of self assurance. Most of the studies conducted in this area have shown that higher chances of developing Coronary Heart Disease and hypertension have been associated with type D personality Disorders (Son and Song, 2008).

Researches conducted in the area of caregivers has often identified various external triggers associated with caregiver burden and stress but various internal factors like personality or temperamental factors or various cognitive distortions is an extremely undermined area of study. Thus assessment and screening of Type D individuals at an early stage will prevent them from developing psychological burden and also help in developing intervention strategies for families of patients with terminal illness and health care professional.

\section{REVIEW OF LITERATURE}

This present study aims to study the role of Type D personality and burden experienced by the caregivers of neurological patients. Thus, few of the studies were reviewed for the above mentioned purpose.

Hoerger, Coerelette et al., (2016) conducted a study on the Spousal Caregivers to understand the the Roles of Neuroticism and Extraversion Personality and Perceived Health of Patients with Lung Cancer using SF- 36 and NEO-FFI. Results indicated that Caregivers with higher scores of Extraversion scores were responded less affirmatively to the item "I expect my health to get worse" and poor perceived health was associated with high neuroticism.

Similarly in an another study conducted by Zang, Li et al., (2011) conducted a cross sectional study on the Chinese adolescents to examine the relationship between type D personality, cognitive distortion, family environment and depression using life orientation test-revised (LOT- 
R), type D personality Scale-14 (DS14), family environment scale (FES), and Zung selfdepression scale (SDS). The results of the study indicated higher level of cognitive distortion, type D personality and adverse family environment was evident among the depressed Chinese adolescents. It also implicated that negative affectivity, lower level of optimism and poor family cohesion can be crucial factors in identifying depression among the vulnerable population.

Various dimensions are being explored in a Meta analytical study conducted by Alarcona, Eschlemana et al., (2009) to find the relationship between burnout and personality factors using Maslach Burnout Inventory (MBI). Results found significant relationship among the dimensions of Maslach Burden inventory i.e. emotional exhaustion, depersonalization, and personal accomplishment with personality factors like self-esteem, self-efficacy, locus of control, emotional stability, extraversion, conscientiousness, agreeableness, positive affectivity, negative affectivity, optimism, proactive personality, and hardiness. Thus the study concluded that employee personality variables are related to burnout and can be significant predictors of burnout.

Similarly a secondary study conducted by Song and Son (2008) to examine the relationship between Type D personality and psychosocial risk factor in developing Cardio vascular diseases among elders with chronic disease. The researchers identified twenty eight studies that indicated a strong association of increased morbidity and mortality of cardiovascular diseases associated with type D personality. It has also been assessed that type d personality individuals often receive lesser benefit from medical care treatment and thus are at an higher risk of impaired quality of life.

\section{METHODOLOGY}

The aim of the study was to assess the relationship between Type D personality and the Caregiver burden experienced by the caregivers of neurological patients and also to study the effect of gender variation for the same. Since this is a correlational study the variables chosen as Predictor Variables are Type D personality, Negative Affectivity, Social Inhibition and the Criterion Variable is Caregiver Burden. The study was conducted in the hospitals of Delhi/NCR where 110 primary caregivers (55males and 55females) were assessed using DS14 (Denolett, 2005) and Zarit Burden Interview (Zetit, 1980). Primary caregivers above 18 years whose family members were suffering from neurological illness at least for past 3 months but the caregivers themselves not suffering from any co-morbid physical or psychiatric illness were sampled for the study. Hypotheses were formulated according to the objectives of the study and the obtained findings were analyzed with help of statistical tools like mean, standard deviation, Pearson Correlation, t-test. 


\section{RESULT ANALYSIS AND INTERPRETATION}

Correlational Analysis and Tabular Representation of scores of Caregiver Burden with Type $D$ personality in Males and Females respectively:

At the 0.01 level of significance, Pearson value of correlation between standard score of Caregiver Burden and Type D personality for males were found to be 0.84 . Similarly Correlational value of Burden with Negative Affectivity, Social Inhibition was found to be 0.78 and 0.79 respectively. Thus it was found that Type D personality is positively correlated with Caregiver burden, Type D personality, Negative Affectivity and Social Inhibition assessed among male caregivers of neurological patients $(\mathrm{p}<0.01)$

\begin{tabular}{|c|c|c|c|c|c|}
\hline Gender & Group I & Group II & $\begin{array}{c}\text { R (Df) } \\
\text { Value }\end{array}$ & P Value & $\begin{array}{c}\text { Level Of } \\
\text { Significance }\end{array}$ \\
\hline $\begin{array}{c}\text { Male } \\
\text { Care- } \\
\text { Givers }\end{array}$ & Burden & $\begin{array}{c}\text { Total Type D } \\
\text { Scores }\end{array}$ & 0.87 & 0.00001 & $\begin{array}{c}\text { The Result Is } \\
\text { Significant At P }<0 \\
.01 .\end{array}$ \\
\hline $\begin{array}{c}\text { Female } \\
\text { Care- } \\
\text { Givers }\end{array}$ & Burden & $\begin{array}{c}\text { Total Type D } \\
\text { Scores }\end{array}$ & 0.65 & 0.00001 & $\begin{array}{c}\text { The Result Is } \\
\text { Significant At P }<0 \\
.01\end{array}$ \\
\hline
\end{tabular}

Similarly, at the 0.01 level of significance, Pearson value of correlation between standard score of Caregiver Burden and Type D personality for females were found to be 0.65. Correlational value of Burden with Negative Affectivity, Social Inhibition was found to be 0.56 and 0.60 respectively. Thus it was found that Type D personality is positively correlated with Caregiver burden, Type D personality, Negative Affectivity and Social Inhibition assessed among female caregivers of neurological patients $(\mathrm{p}<0.01)$.

\section{Result Analysis of sample distribution based on Type D personality and Burden in male and female caregivers:}

Out of 110 sample size, 73 of them are suffering from Caregiver burden and among them, 41 are males and 32 are females. And 63 of them out of 110 sample sizes are assessed to have Type D personality, among them 37 being males and 26 being females. 
Type- D Personality and Burden among the Caregivers of Neurological Patients

Graphical Representation Showing the Sample Distribution Gender Wise Based On Type D Personality and Burden in Male and Female Caregivers

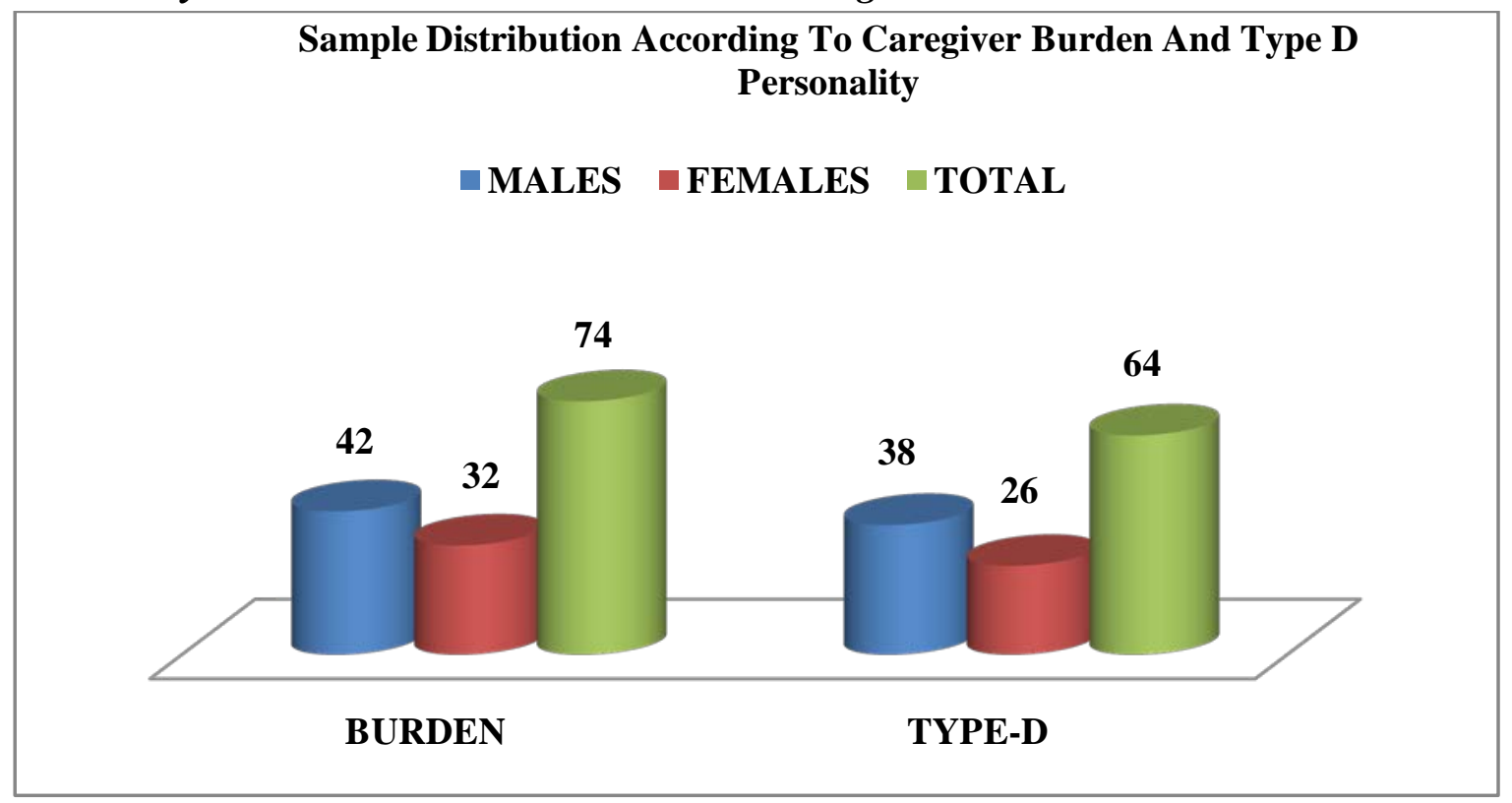

t- Test analysis and Scatter Plot Representation scores of male and female caregivers who were assessed with Type- D personality and Caregiver Burden among the caregivers of neurological patients.

At the 0.05 level of significance, $t$ value is 0.57 for $\mathrm{p}=0.56$ for difference between male and female caregivers who experience Caregiver Burden. Thus no significant difference was found between male and female caregivers who experience Caregiver Burden among the caregivers of neurological patients. $(\mathrm{p}<0.05)$.

And, $\mathrm{t}$ value is 0.78 for $\mathrm{P}=0.44$ for difference between male and female caregivers who were assessed with Type D personality, at the 0.05 level of significance. Thus no significant difference was found between male and female caregivers who were assessed with Type D personality among the caregivers of neurological patients $(\mathrm{p}<0.05)$.

(c) The International Journal of Indian Psychology, ISSN 2348-5396 (e)| ISSN: 2349-3429 (p) | 146 
Type- D Personality and Burden among the Caregivers of Neurological Patients

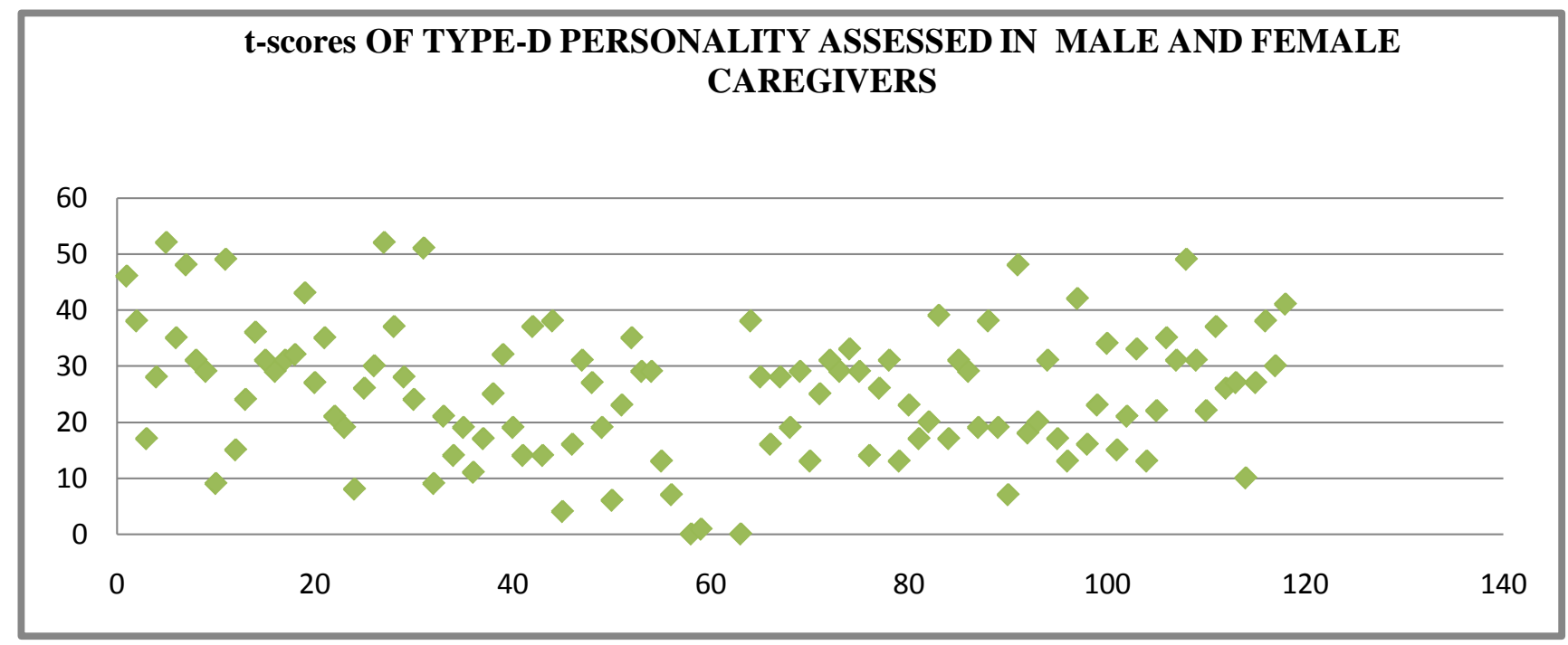

\section{DISCUSSION}

According to findings from the study it is seen that, there is a significant positive correlation of Caregiver Burden with Type D personality in male care givers of neurological patients and thus raising more chance to worst health outcomes and prognosis. This has been validated by a study where it mentions that Type D personality is often a predictor of worse health outcomes like various coronary Heart Diseases, other health issues and mental health issues that are often similarly correlated with Type A personality behaviors like being impulsive, irritated, being competitive and developing aggressiveness (Denolett, 1998a).

Similar results were validated for even female caregivers which showed a strong significant correlation between Type D personality and Burden Experienced by female caregivers of Neurological patients. A study by Hoerger, Coerelette et al., (2016) indicated that Caregivers with higher scores of Neuroticism and lower scores on Extraversion scores and poor perceived health was associated with high caregiver burden.

Thus, the findings of the study similarly have found a strong significant positive correlation of Negative Affectivity with Caregiver Burden in males as well females. $(\mathrm{p}<0.01)$. The results have been substantiated by a study conducted by Zang, Li et al., (2011) on the Chinese adolescent and found that negative affectivity, lower level of optimism and poor family cohesion can be crucial factors in identifying depression among the vulnerable population.

Similarly other results have shown that there is a significant positive correlation of Social Inhibition with Type $\mathrm{D}$ personality in males as well females $(\mathrm{p}<0.01)$. Results of a study conducted by Alarcona, Eschlemana et al., (2009) found personality factors like emotional exhaustion, depersonalization, and personal accomplishment with personality factors like selfesteem, self-efficacy, locus of control, emotional stability, extraversion, conscientiousness, 
agreeableness, positive affectivity, negative affectivity, optimism, proactive personality, and hardiness can be significant predictors of burnout.

No significant difference was found between male and female caregivers who were assessed with Type D personality among the caregivers of neurological patients $(p<0.05)$. Similarly, no significant difference was found between male and female caregivers who experience Caregiver Burden among the caregivers of neurological patients. $(p<0.05)$. Although results showed that gender has miniscule effect on experience of caregiver burden but this contradicts to few of the old literatures which mentions that females especially mothers experience more caregiver burden than the male caregivers (Maheshwari, 2014, Dada, Niran et al., 2011).

\section{SUMMARY \& CONCLUSION}

The aim of the study was to assess the Type D personality and Caregiver burden among the caregivers of neurological patients and find the correlation of Caregiver Burden with Type D personality. The study was conducted on 110 caregivers of neurological patients at hospitals located in Delhi/ NCR with the help of assessment sales like Zarit Burden Interview (ZBI) and DS14. The study hypothesized a correlation between Caregiver burden with Type D personality, Negative Affectivity and Social Inhibition among both male as well female caregivers and a significant difference between Male and female Caregiver Burden and assessment of Type D personality.

Thus the study has succeeded in exploring the strong correlation between Type D personality and its characteristics like Negative Affectivity and Social Inhibition with the burden experienced by the caregivers of the neurological patients for both males as well female caregivers. But results found miniscule or no effect of gender on neither experiencing of Caregiver Burden nor assessment of Type D personality among the male and female caregivers of Neurological Patients.

\section{PRACTICAL IMPLICATIONS OF THE STUDY}

- Assessment of Type D individuals and screening them at an early stage can help them to prevent from developing psychological burden or physical dysfunctions like Cardio vascular disorders, Hypertension from any stressful jobs like medical and healthcare services for terminally ill patients.

- Screening of Type D Personality factors by the school psychologists or the career counselors among the children and the adolescents to choose career options that are less challenging in terms of caregiver burden like Nursing, Clinical Psychologists, General physicians, Psychiatrists, Surgeons, Volunteers, Special Educators, Rehabilitation Therapists etc can help to prevent any kind of distress, burden or burnout in any phase of their lives. 


\section{LIMITATIONS}

- This study is a cross sectional study that assess the presence of caregiver burden and Type D personality among the Caregivers of Neurological patients on a limited time period.

- Studying the effect of gender on a smaller sample ratio without controlling any age group can be the drawback of this study

\section{FUTURE RECOMMENDATIONS}

- A longitudinal study or an in-depth qualitative study with pre and post assessment over an extensive time period will give a better insight to understand whether Type D predicts Caregiver Burden or vice versa to replicate the results with more validity and help in generalizing the results.

- Overcoming the limitations of gender on sample size with modification of age and other related variables can help to generalize the study results on a representative population

\section{Acknowledgments}

The author appreciates all those who participated in the study and helped to facilitate the research process.

\section{Conflict of Interests}

The author declared no conflict of interests.

\section{REFERENCES}

Alarcon, G., Eschleman, K. J., \& Bowling, N. A. (2009). Relationships between personality variables and burnout: A meta-analysis. Work \& stress, 23(3), 244-263

Chadda, R. K. (2014). Caring for the family caregivers of persons with mental illness. Indian journal of psychiatry, 56(3), 221.

Dada, M. U., Okewole, N. O., Ogun, O. C., \& Bello-Mojeed, M. A. (2011). Factors associated with caregiver burden in a child and adolescent psychiatric facility in Lagos, Nigeria: a descriptive cross sectional study.BMC pediatrics, 11(1), 1.

Denollet, J. (1998a) Personality and coronary heart disease: the type-D scale 16 (DS16). Annals of Behavioral Medicine, 1998, 20, 209-215.

Denollet, J. K. L. (2000). Type D personality: A potential risk factor refined. Journal of Psychosomatic Research. 49. 255-266.

Hoerger, M., Coletta, M., Sörensen, S., Chapman, B. P., Kaukeinen, K., Tu, X., \& Duberstein, P. R. (2016). Personality and Perceived Health in Spousal Caregivers of Patients with Lung Cancer: The Roles of Neuroticism and Extraversion. Journal of aging research.

Maheshwari, K. (2014) "Burden of care givers of mentally retarded children." IOSR Journal of Humanities and Social Science 19.7: 6-12. 
Type- D Personality and Burden among the Caregivers of Neurological Patients

Zetit. S. H, Reever. K. E, Bach-Peterson (1980). Relatives of the impaired elderly: correlates of feelings of burden. Gerontologist; 20:649-55.

Zhang, Y., Li, H., \& Zou, S. Association between Cognitive Distortion, Type D Personality, Family Environment, and Depression in Chinese Adolescents. Depression research and treatment. 2011; 2011: 143045. External Resources Pubmed/Medline (NLM) CrossRef (DOI).

How to cite this article: Chattopadhyay R, Sharma A (2017), Type- D Personality and Burden among the Caregivers of Neurological Patients, International Journal of Indian Psychology, Volume 4, Issue 2, No. 96, ISSN:2348-5396 (e), ISSN:2349-3429 (p), DIP:18.01.196/20170402, ISBN:978-1-365-84232-0

(c) The International Journal of Indian Psychology, ISSN 2348-5396 (e)| ISSN: 2349-3429 (p) | 150 